\title{
Increasing Veno-Arterial Extracorporeal Membrane Oxygenation Flow Reduces Electrical Impedance of the Lung Regions in Porcine Acute Heart Failure
}

\author{
Michaela POPKOVÁ ${ }^{1}$, Eduard KURIŠČÁK ${ }^{1}$, Pavel HÁLA ${ }^{1,2}$, David JANÁK ${ }^{1,3}$, Leoš \\ TEJKL ${ }^{1}$, Jan BĚLOHLÁVEK ${ }^{4}$, Petr OŠŤÁDAL ${ }^{2}$, Petr NEUŽIL ${ }^{1,2}$, Otomar KITTNAR ${ }^{1}$, \\ Mikuláš MLČEK ${ }^{1}$
}

${ }^{1}$ Department of Physiology, First Faculty of Medicine, Charles University, Prague, Czech Republic, ${ }^{2}$ Department of Cardiology, Na Homolce Hospital, Prague, Czech Republic, ${ }^{3}$ Department of Cardiovascular Surgery, Second Faculty of Medicine, Charles University and University Hospital Motol, Prague, Czech Republic, ${ }^{4}$ Second Department of Medicine - Cardiovascular Medicine, First Faculty of Medicine, Charles University and General University Hospital, Prague, Czech Republic

Received January 6, 2020

Accepted April 22, 2020

Epub Ahead of Print June 25, 2020

\begin{abstract}
Summary
Veno-arterial extracorporeal membrane oxygenation (VA ECMO) is a technique used in patients with severe heart failure. The aim of this study was to evaluate its effects on left ventricular afterload and fluid accumulation in lungs with electrical impedance tomography (EIT). In eight swine, incremental increases of extracorporeal blood flow (EBF) were applied before and after the induction of ischemic heart failure. Hemodynamic parameters were continuously recorded and computational analysis of EIT was used to determine lung fluid accumulation. With an increase in EBF from 1 to $4 \mathrm{l} / \mathrm{min}$ in acute heart failure the associated increase of arterial pressure (raised by $44 \%$ ) was accompanied with significant decrease of electrical impedance of lung regions. Increasing EBF in healthy circulation did not cause lung impedance changes. Our findings indicate that in severe heart failure EIT may reflect fluid accumulation in lungs due to increasing EBF.
\end{abstract}

\section{Key words}

Extracorporeal membrane oxygenation - Electrical impedance tomography • Pulmonary edema • Swine

\section{Corresponding author}

Mikuláš Mlček, Department of Physiology, First Faculty of Medicine, Charles University, Albertov 5, 12800 Prague 2, Czech Republic. E-mail: mikulas.mlcek@lf1.cuni.cz

\section{Introduction}

Veno-arterial extracorporeal membrane oxygenation (VA ECMO) is a lifesaving method used in patients with severe circulatory failure refractory to conventional management (Abrams et al. 2014, Makdisi and Wang 2015). It can substitute lungs and support circulation since it enables blood gas exchange (oxygenation and carbon dioxide extraction), improves tissue perfusion (Hala et al. 2016, Lequier et al. 2017), and serves as a bridge of the critical period (Ostadal et al. 2018). Blood is bypassed from the native circulation through percutaneous venous cannula to the gas exchange unit and after being oxygenated, it is returned into the descending aorta. Blood from VA ECMO is thus mixed with the blood pumped by the left ventricle (LV). Recent papers have discussed the negative effects of increased afterload on the LV function (Fuhrman et al. 1999, Soleimani and Pae 2012, Ostadal et al. 2015, Brechot et al. 2017, Donker et al. 2019, Hála et al. 2020), which may lead to LV distension, a rise in the end-diastolic volume, end-systolic volume, end-diastolic pressure, and in left atrial pressure. Progression into pulmonary edema may consequently occur (Fuhrman et al. 1999, Burkhoff et al. 2015, Ostadal et al. 2015, Ostadal et al. 2018, Donker et al. 2019). Furthermore, clinical work by Kim 
et al. (2018) recently described how excessive cumulative fluid balance during early phases of ECMO increases the risk of mortality.

Pulmonary edema is a serious complication of VA ECMO, especially in patients with severely impaired left ventricular function. Therefore, it often requires urgent intervention (Fuhrman et al. 1999, Brechot et al. 2017, Donker et al. 2019). Currently, standard diagnostic procedures to detect pulmonary edema are based on clinical examination, lung ultrasound, echocardiography, chest radiography, and hemodynamics assessment. However, these methods are lacking the sensitivity to quantify fluid volumes (Cardinale et al. 2014) and may require repeated evaluations. Real-time diagnostic methods (e.g. transpulmonary thermodilution) are also available, however, requiring additional invasive procedure and lacking high sensitivity (Sobota et al. 2019).

Electrical impedance tomography (EIT) is a bedside, non-invasive, radiation-free, and real-time imaging technique based on the assessment of tissue resistivity. This is best represented by the physical quantity called impedance, obtained by probing the tissue with skin electrodes injecting a weak alternating current (excitation frequency ranges from tens to hundreds of $\mathrm{kHz}$ ). Currently, it is being used for bedside monitoring of regional lung ventilation and the distribution of air within the lungs, especially in patients with acute lung injury and acute respiratory distress syndrome (Frerichs et al. 2017, Bachmann et al. 2018). Due to the air space in the alveoli, native resistivity of lung tissue is high and electrical impedance varies considerably with breathing cycles reaching peak values during inspiration. Conversely, impedance of plasma is low and therefore increased volume of fluid in lungs has a considerable effect on decreasing tissue electrical impedance. Sobota et al. (2019) and Becher et al. (2019) recently demonstrated in both animal experiments and clinical practice that intravenous administration of fluids has a significant effect on the lung impedance. Therefore, EIT can serve as a suitable method for bedside evaluation of small fluid changes in the lungs (Adler et al. 1997, Noble et al. 2000). Moreover, the diagnostic potential of EIT can be further increased using advanced signal analysis, which allows for the evaluation of the regional perfusion and heart work (Borges et al. 2012, Reinius et al. 2015).

The purpose of this pilot study was to evaluate the acute fluid changes in the lungs during VA ECMO support. Lung impedance changes were registered during incremental increases in VA ECMO blood flow under both healthy and failing heart conditions. We present a new computational analysis of the raw EIT data which detects minor changes in fluid content specifically within the lung tissue.

\section{Methods}

Experimental protocol was reviewed and approved by the Institutional Animal Expert Committee of the Fist Faculty of Medicine, Charles University and was performed at the University experimental laboratory, Department of Physiology, First Faculty of Medicine, Charles University, Prague, Czech Republic, in accordance with Act No 246/1992 Coll. on the protection of animals against cruelty. All animals were treated and cared in accordance with the European Guidelines on Laboratory Animal Care.

\section{Animal model}

Eight healthy female pigs (Sus scrofa domestica), weight $57 \pm 2 \mathrm{~kg}$, were included in this study. After 12 hours of fasting, animals were premedicated with midazolam (0.2-0.4 mg/kg IM) and ketamine (15-25 $\mathrm{mg} / \mathrm{kg} \mathrm{IM}$ ), then marginal ear vein access was secured, and induction of anesthesia was achieved by intravenous application of propofol ( $2 \mathrm{mg} / \mathrm{kg}$ IV). The animals were positioned into the dorsal recumbency before the endotracheal intubation was performed (tube 7-8 mm). Mechanical ventilation was operated by Hamilton G5 ventilator (Hamilton Medical AG, Switzerland), set to volume control ventilation described in more detail in the ECMO protocol section. The position of the animals was stable during the whole experiment.

Total intravenous anesthesia was maintained during the experiment. Propofol $(6-10 \mathrm{mg} / \mathrm{kg} / \mathrm{h})$ and midazolam $(0.1-0.2 \mathrm{mg} / \mathrm{kg} / \mathrm{h})$ were combined with opiate analgesia (morphine $0.1-0.3 \mathrm{mg} / \mathrm{kg} / \mathrm{h}$ ), and the depth of anesthesia was confirmed by controlling reflexes, muscle tone, and cardiovascular reactions. Continuous infusions of heparin (50-80 UI/ $\mathrm{kg} / \mathrm{h})$ was set to prevent thrombosis. Infusion of Ringer's solution and $0.9 \%$ saline was kept within range $5-10 \mathrm{ml} / \mathrm{kg} / \mathrm{h}$ to maintain central venous pressure (CVP) around $5 \mathrm{mmHg}$ before the ECMO implantation. Foley catheter was inserted through the urethra to the urinary bladder to monitor urine production. 


\section{Experimental preparation and monitoring}

A triple lumen central venous catheter was placed percutaneously through the external jugular vein for CVP monitoring, as well as for fluid and anesthetics administration. The femoral artery was cannulated to measure systemic blood pressure. A balloon Swan-Ganz catheter was inserted into the pulmonary artery via the femoral vein to simultaneously record pulmonary artery pressure, mixed venous oxygen saturation $\left(\mathrm{SvO}_{2}\right)$, and cardiac output (CCO Combo Catheter, Vigilance II, Edwards Lifesciences, USA), whereas pulmonary capillary wedge pressure (PCWP) was measured upon completion of each ECMO flow step. The right carotid artery was surgically exposed, and an ultrasound flow probe was placed around the vessel (4PSB or 6PSB, Transonic Systems, USA) to continuously measure the blood flow. Regional tissue oxygenation $\left(\mathrm{rSO}_{2}\right)$ was monitored by near-infrared spectroscopy (INVOS Oximeter, Medtronic, USA) with sensors placed on forehead and right forelimb, to evaluate head and peripheral tissue oxygen saturation.

\section{Electrical impedance tomography}

Swisstom EIT-Pioneer set (Swisstom, AG, Switzerland) was used to measure the electrical impedance tomography of the thorax. The sensor belt, fitted with 32 evenly distributed electrodes, was placed around the circumference of the thorax and its position was verified by X-ray to ensure its proper position above the diaphragm around both lungs and the heart. Alternating electrical current of single frequency ( $3 \mathrm{~mA}$, $200 \mathrm{kHz}$ ) was applied through pairs of electrodes and corresponding voltages were measured on the remaining electrodes. The pattern of the injecting and sensing electrodes was rearranged automatically, achieving apparent rotatory movement of probing electrodes around the chest, resembling the way the computed tomography image is obtained. This allows for the real-time (update rate $50 \mathrm{~Hz}$ ) reconstruction of the tissue impedance, generating a $64 \times 64$ pixel matrix every $20 \mathrm{~ms}$, and so creating a dynamic $2 \mathrm{D}$ image of the thoracic tomographic plane.

\section{Veno-arterial extracorporeal membrane oxygenation}

Extracorporeal membrane oxygenation in venoarterial setting (VA ECMO) was used. The dosage of heparin was set to keep activated clotting time at 200-300 s. ECMO cannulas were introduced by Seldinger technic through punctures of the ipsilateral femoral vein and artery. The tip of the inflow venous cannula (21 Fr) was placed near the right atrium and the arterial outflow cannula (15 Fr) was placed in the descending aorta. The

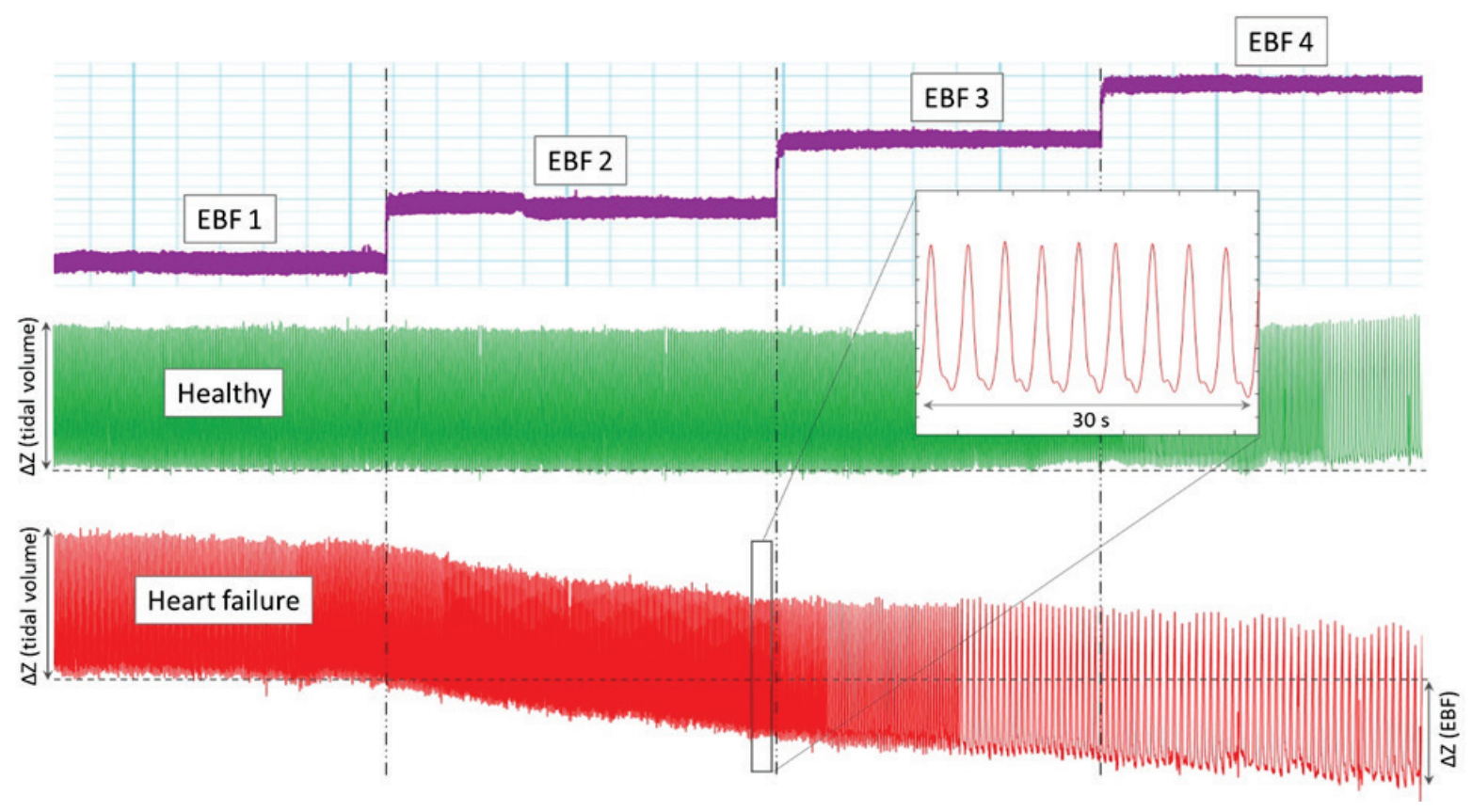

Fig. 1. Representative example of EIT waveforms from one animal. Stepwise changes with increasing VA ECMO flows (purple) are aligned with electrical impedance for both healthy (green) and heart failure (red) conditions. Electrical impedance waveforms represent impedance of lung regions during breathing cycles. End-expiratory impedance was evaluated at the end of each EBF step and with increasing EBF it did not change in healthy condition but decreased significantly in heart failure. $\Delta Z$ (tidal volume) represents the change in electrical impedance during breathing cycle (tidal volume), whereas $\Delta Z$ (EBF) represents change in impedance with increased $\mathrm{EBF}$ (EBF 1 to $\mathrm{EBF} 4 \mathrm{l} / \mathrm{min}$ ). $\Delta \mathrm{Z}$ (EBF) is approximately $60 \%$ of the $\Delta \mathrm{Z}$ (tidal volume) in this animal. 
position of both cannulas was verified by fluoroscopy. Extracorporeal blood flow (EBF) was measured by the flow probe (ME 9PXL, Transonic, USA) attached to the outflow cannula. Blood gas parameters were monitored continuously in the blood leaving the oxygenator $\left(\mathrm{CDI}^{\mathbb{B}}\right.$ Blood Parameter Monitoring System 500, Terumo Cardiovascular System Corporation, USA). The oxygen and air flow were adjusted to maintain arterial $\mathrm{pO}_{2}$ at $150-200 \mathrm{mmHg}$ and $\mathrm{pCO}_{2}$ at $35-45 \mathrm{mmHg}$.

\section{ECMO protocol}

After the introduction of VA ECMO, the defined protocol (Fig. 1) with increasing EBF was applied to healthy cardiovascular system (before the induction of HF). Lungprotective ventilation was set to volume control: tidal volume $\left(\mathrm{V}_{\mathrm{T}}\right) 6-7 \mathrm{ml} / \mathrm{kg}$, positive end-expiratory pressure (PEEP) 5-6 $\mathrm{cmH}_{2} \mathrm{O}$, peak inspiratory pressure $\mathrm{PIP}<$ $25 \mathrm{cmH}_{2} \mathrm{O}$, fraction of inspired oxygen $\left(\mathrm{FiO}_{2}\right) 30 \%$. $\mathrm{V}_{\mathrm{T}}$ and PEEP were kept constant during the protocol and the respiratory rate was adjusted to maintain end-tidal $\mathrm{CO}_{2}$ $\left(\mathrm{etCO}_{2}\right) \quad 35-45 \mathrm{mmHg}$. Administration of intravenous infusions was constant throughout the protocol $(5-6 \mathrm{ml} / \mathrm{kg} / \mathrm{h})$. VA ECMO flow was increased stepwise with $20 \mathrm{ml} / \mathrm{kg} / \mathrm{min}$ increments, starting at $20 \mathrm{ml} / \mathrm{kg} / \mathrm{min}$ (referred to as EBF $11 / \mathrm{min}$ ) and reaching up to $80 \mathrm{ml} / \mathrm{kg} / \mathrm{min}$ (EBF 4 1/min). Each step lasted 8-12 min. At the end of each step lung impedance and hemodynamic parameters were obtained by averaging end-expiratory values during $30 \mathrm{~s}$.

\section{Heart failure}

A model of acute HF was used in our experiment. Based on previous publications (Suzuki et al. 2008, Ishikawa et al. 2014, Li et al. 2014) and our own experience (Ostadal et al. 2016, Janak et al. 2017, Hala et al. 2018, Lacko et al. 2018), an ischemic HF model was induced by fluoroscopically controlled proximal occlusion of the left anterior descending coronary artery (LAD) with a balloon-tip catheter (balloon $4 \times 20 \mathrm{~mm}$ or $5 \times 20 \mathrm{~mm}$ ). Amiodarone was administered (150-300 mg IV) prior to the occlusion. LAD occlusion lasted for 40-50 min. In case the ventricular fibrillation (VF) occurred, the ECMO flow of $60 \mathrm{ml} / \mathrm{kg} / \mathrm{min}$ was used to substitute the systemic circulation. Defibrillation was then performed after the balloon deflation. Moreover, if MAP dropped below $50 \mathrm{mmHg}$, continuous infusion of norepinephrine $(0.01-0.1 \mathrm{mcg} / \mathrm{kg} / \mathrm{min})$ was started and titrated at the lowest rate to maintain MAP $50-60 \mathrm{mmHg}$.

Subsequently, identical VA ECMO protocol as described above was applied to conditions of acute ischemic heart failure, and hemodynamic and lung impedance values were compared to those acquired with the healthy circulation.

\section{Electrical impedance data analysis}

As mentioned above, the $64 \times 64$ pixel matrix of impedances was continuously generated throughout the whole experiment with an update rate of $50 \mathrm{~Hz}$, creating a dynamic, real-time, cross-sectional, 2D thorax map, at the position of the EIT sensor belt. In time domain, each pixel of that matrix represents the time-course of reconstructed electrical impedance of corresponding thorax tissue region. To filter out frequencies higher than those related to breathing, we rejected all frequencies above $1 \mathrm{~Hz}$ by low-pass filter. Furthermore, to isolate the lung regions, we filtered out other chest areas, by discarding pixels (matrix elements) that were more than $0.8 \pi$ cycle out of breathing phase, as viewed from the $0 \pi$ phase pixel representing the center of the lungs (Fig. 2).
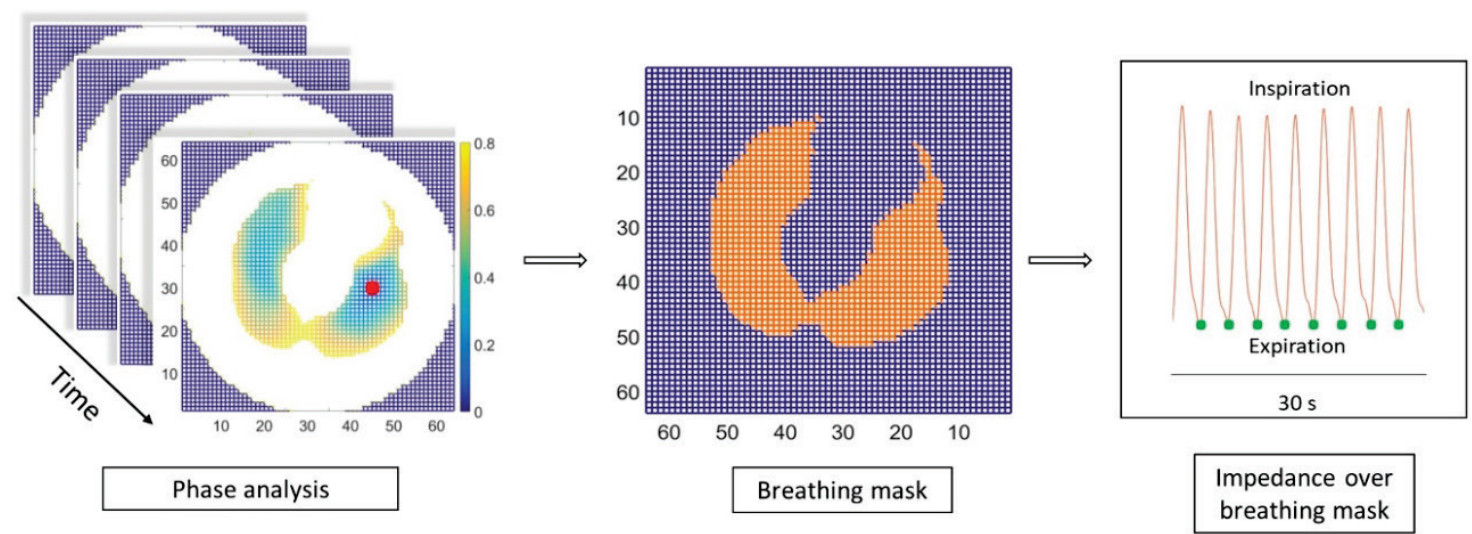

Fig. 2. Analysis of EIT signal. To the left, $64 \times 64$ impedance matrix and corresponding colorbar map show the phase delay from the reference pixel of zero phase (red dot), representing the center of the left lung. In the middle, resulting breathing mask (orange) defines pixels which were analyzed at expiration (green dots), averaged over this mask region, and normalized to the EIT value obtained at EBF $1 \mathrm{l} / \mathrm{min}$. EBF - extracorporeal blood flow, EIT - electrical impedance tomography. 
Pixels being less than $0.8 \pi$ from the $0 \pi$ reference point set up the breathing mask at the beginning of each experiment. Then, the impedance was averaged over this mask region only (summing all impedances of those pixels, divided by the number of pixels in the mask), giving us the course of impedance of whole lungs in time. These EIT values registered at the end of expiration averaged over the last $30 \mathrm{~s}$ of each EBF step, were further processed. To eliminate interindividual variability of absolute lung impedance, values of lung impedance were rescaled by normalization. Within the time frame of one ECMO protocol, impedance values taken at various EBF steps were normalized with respect to the EBF of $11 / \mathrm{min}$ (assigned with reference impedance set to 1).

\section{Statistical analysis}

Except the electrical impedance, recordings were sampled at $400 \mathrm{~Hz}$ by PowerLab A/D converted and continuously recorded by LabChart Pro Software (ADInstruments, Australia). EIT data were analyzed in MATLAB (The MathWorks, USA) and normalized to baseline value measured at $1 \mathrm{l} / \mathrm{min}$ of EBF. Statistical analyses were performed in GraphPad Prism 7 (GraphPad Software, USA) and Excel (Microsoft, USA).

All results are expressed as mean \pm standard error of mean (SEM). The differences among individual levels of EBF were analyzed using a repeated-measures one-way ANOVA with Tukey's multiple comparison test or using the Friedman test with Dunn's multiple comparison test (for data sets without normal distribution). Success in heart failure induction was verified using the Wilcoxon signed-rank test. A P value of $<0.05$ was considered statistically significant.

Table 1. Hemodynamic parameters of heart failure induced by myocardial ischemia.

\begin{tabular}{|c|c|c|c|c|c|c|c|}
\hline \multirow[b]{2}{*}{${ }_{p} C O$} & \multirow[b]{2}{*}{$\mathrm{l} / \mathrm{min}$} & \multicolumn{2}{|c|}{ Healthy } & \multicolumn{2}{|c|}{ Heart failure } & \multirow{2}{*}{$\begin{array}{c}\text { P value } \\
<0.01\end{array}$} & \multirow{2}{*}{$\begin{array}{l}\text { Change } \\
-47 \%\end{array}$} \\
\hline & & 5.5 & 0.7 & 2.9 & $\pm \quad 0.3$ & & \\
\hline$M A P$ & $\mathrm{mmHg}$ & 76 & \pm 5 & 51 & $\pm \quad 4$ & $<0.01$ & $-33 \%$ \\
\hline Carotid flow & $\mathrm{ml} / \mathrm{min}$ & 419 & 37 & 248 & $\pm \quad 22$ & $<0.05$ & $-41 \%$ \\
\hline $\mathrm{SvO} \mathrm{O}_{2}$ & $\%$ & 76 & \pm 3 & 59 & \pm 6 & $<0.01$ & $-23 \%$ \\
\hline $\mathrm{rSO}_{2}$ head & $\%$ & 72 & \pm 2 & 54 & \pm 3 & $<0.05$ & $-25 \%$ \\
\hline
\end{tabular}

Values expressed as mean \pm SEM. Last column presents the relative change between healthy and heart failure. Parameters were obtained with $1 \mathrm{l} / \mathrm{min}$ of EBF before start of the ECMO protocol. EBF - extracorporeal blood flow, ECMO - extracorporeal membrane oxygenation, MAP - mean arterial pressure, ${ }_{\mathrm{p}} \mathrm{CO}$ - cardiac output measured using a pulmonary artery catheter, $\mathrm{rSO}_{2}$ head - regional tissue oxygenation measured on forehead, $\mathrm{SvO}_{2}$ - mixed venous oxygen saturation.

\section{Results}

Hemodynamic characteristics of the model before (healthy) and after the acute heart failure (HF) induction are summarized in Table 1. Ventricular fibrillation occurred in all animals within the first ten minutes of LAD occlusion. It was successfully terminated by an external defibrillation. HF induction had a significant effect on all major hemodynamic parameters: cardiac output decreased from $5.5 \pm 0.7$ to $2.9 \pm 0.31 / \mathrm{min}(\mathrm{P}<0.01)$, MAP from $76 \pm 5$ to $51 \pm 4 \mathrm{mmHg}$ $(\mathrm{P}<0.01)$, carotid flow from $419 \pm 37$ to $248 \pm 22 \mathrm{ml} / \mathrm{min}$ $(\mathrm{P}<0.05)$, and mixed venous oxygen saturation and $\mathrm{rSO}_{2}$ on forehead decreased by $23 \%$ and $25 \%$, respectively (for both $\mathrm{P}<0.05$ ). All these parameters were obtained with $11 /$ min of EBF support, before the start of each ECMO protocol. Moreover, five animals required norepinephrine administration (0.01-0.1 $\mathrm{ml} / \mathrm{kg} / \mathrm{min})$ during EBF 1 to prevent severe hypotension. In these animals, norepinephrine was discontinued after MAP reached $60 \mathrm{mmHg}$.

VA ECMO effects on hemodynamics and electrical impedance are detailed in Table 2 and Figure 3. With the same VA ECMO protocol applied to the healthy and the heart failure conditions, we have observed different effects on electrical impedance of the lung regions. With increasing EBF from 1 to $4 \mathrm{l} / \mathrm{min}$ the normalized lung impedance did not change in the healthy circulation but declined with each EBF step in HF group - from $1 \pm 0.0$ to $0.986 \pm 0.009, \quad 0.979 \pm 0.014$, and $0.974 \pm 0.017$ (for $\mathrm{EBF} 1$ to $4 \mathrm{l} / \mathrm{min}, \mathrm{P}<0.001$ ). Figure 1 shows an example of full trends of electrical impedance over the ECMO protocol in healthy and HF conditions.

In stepwise ECMO protocol applied to the 
Table 2. Comparison of the effects of extracorporeal blood flow on hemodynamic parameters and electrical impedance of lungs in healthy circulation and heart failure conditions.

\begin{tabular}{|c|c|c|c|c|c|c|}
\hline & $l / \min$ & $\begin{array}{c}\text { EBF 1 } \\
\text { Healthy }\end{array}$ & $\begin{array}{c}\text { EBF } 2 \\
\text { Healthy }\end{array}$ & $\begin{array}{c}\text { EBF } 3 \\
\text { Healthy }\end{array}$ & $\begin{array}{c}\text { EBF } 4 \\
\text { Healthy }\end{array}$ & $\begin{array}{l}\text { P value } \\
\text { Healthy }\end{array}$ \\
\hline$M A P$ & $m m H g$ & $75 \pm 5$ & $84 \pm 5$ & $* 87 \pm 6$ & $* * 92 \pm 6$ & $<0.01$ \\
\hline Carotid flow & $\mathrm{ml} / \mathrm{min}$ & $395 \pm 26$ & $425 \pm 30$ & $* 456 \pm 31$ & $435 \pm 38$ & $<0.05$ \\
\hline$M P A P$ & $m m H g$ & $29 \pm 4$ & $27 \pm 4$ & $* 24 \pm 3$ & $* * 23 \pm 3$ & $<0.001$ \\
\hline$P C W P$ & $m m H g$ & $5.4 \pm 0.9$ & $5.4 \pm 0.9$ & $5.1 \pm 0.5$ & $4.4 \pm 0.6$ & $<0.05$ \\
\hline$C V P$ & $\mathrm{mmHg}$ & $4.4 \pm 0.5$ & $3.9 \pm 0.5$ & $3.3 \pm 0.6$ & $* 2.6 \pm 0.7$ & $<0.01$ \\
\hline $\mathrm{SvO}_{2}$ & $\%$ & $76 \pm 3$ & $80 \pm 3$ & $* 82 \pm 2$ & $* 83 \pm 3$ & $<0.01$ \\
\hline $\mathrm{rSO}_{2}$ head & $\%$ & $72 \pm 2$ & $73 \pm 2$ & $* 76 \pm 2$ & $* * 76 \pm 1$ & $<0.01$ \\
\hline$r \mathrm{SO}_{2} \operatorname{limb}$ & $\%$ & $69 \pm 2$ & $69 \pm 2$ & $69 \pm 2$ & $70 \pm 2$ & ns \\
\hline \multirow[t]{2}{*}{$E I T$} & & 1.000 & $0.999 \pm 0.006$ & $1.006 \pm 0.007$ & $1.006 \pm 0.009$ & ns \\
\hline & $l / \min$ & $\begin{array}{c}\text { EBF } 1 \\
\text { Heart failure }\end{array}$ & $\begin{array}{c}\text { EBF } 2 \\
\text { Heart failure }\end{array}$ & $\begin{array}{c}\text { EBF } 3 \\
\text { Heart failure }\end{array}$ & $\begin{array}{c}\text { EBF } 4 \\
\text { Heart failure }\end{array}$ & $\begin{array}{c}\text { P value } \\
\text { Heart failure }\end{array}$ \\
\hline$M A P$ & $m m H g$ & $52 \pm 5$ & $53 \pm 5$ & $60 \pm 4$ & $* * 74 \pm 6$ & $<0.01$ \\
\hline Carotid flow & $\mathrm{ml} / \mathrm{min}$ & $258 \pm 28$ & $310 \pm 43$ & $319 \pm 23$ & $* * 410 \pm 34$ & $<0.01$ \\
\hline$M P A P$ & $m m H g$ & $32 \pm 4$ & $29 \pm 5$ & $25 \pm 3$ & $25 \pm 3$ & ns \\
\hline$P C W P$ & $m m H g$ & $8.3 \pm 1.9$ & $8.8 \pm 2.0$ & $10.5 \pm 2.1$ & $* 10.3 \pm 1.8$ & $<0.001$ \\
\hline$C V P$ & $m m H g$ & $7.5 \pm 0.5$ & $6.5 \pm 0.5$ & $6.0 \pm 0.5$ & $* 5.1 \pm 0.4$ & $<0.01$ \\
\hline $\mathrm{SvO}_{2}$ & $\%$ & $56 \pm 6$ & $67 \pm 4$ & $* 74 \pm 3$ & $* * * * 84 \pm 4$ & $<0.0001$ \\
\hline $\mathrm{rSO}_{2}$ head & $\%$ & $52 \pm 4$ & $54 \pm 5$ & $61 \pm 3$ & $* * 66 \pm 3$ & $<0.01$ \\
\hline$r \mathrm{SO}_{2} \operatorname{limb}$ & $\%$ & $58 \pm 3$ & $61 \pm 2$ & $62 \pm 3$ & $* * 65 \pm 3$ & $<0.01$ \\
\hline$E I T$ & & 1.000 & $0.986 \pm 0.003$ & $* * 0.9785 \pm 0.005$ & $* * * 0.9744 \pm 0.006$ & $<0.001$ \\
\hline
\end{tabular}

Values expressed as mean \pm SEM. Values significantly different to $1 \mathrm{l} / \mathrm{min}$ (EBF 1 ) are marked with $*$ for $\mathrm{P}<0.05, * *$ for $\mathrm{P}<0.01, * * *$ for $\mathrm{P}<0.001$, $* * * *$ for $\mathrm{P}<0.0001$. The $\mathrm{P}$ values reflect the whole EBF trend statistics. CVP - central venous pressure, EBF - extracorporeal blood flow, EIT - electrical impedance normalized to EBF 1, MAP - mean arterial pressure, MPAP - mean pulmonary artery pressure, $\mathrm{PCWP}$ - pulmonary capillary wedge pressure, $\mathrm{ns}$ - non-significant, $\mathrm{rSO}_{2}$ - regional tissue oxygenation, $\mathrm{SvO}_{2}$ - mixed venous oxygen saturation.

healthy circulation, with increasing EBF (from EBF 1 to $4 \mathrm{l} / \mathrm{min}$ ) MAP increased from $75 \pm 5$ to $92 \pm 6 \mathrm{mmHg}$ $(\mathrm{P}<0.01)$ and mean carotid flow from $395 \pm 26$ to $435 \pm 38 \mathrm{ml} / \mathrm{min}(\mathrm{P}<0.05)$. MPAP decreased from $29 \pm 4$ to $23 \pm 3 \mathrm{mmHg}(\mathrm{P}<0.001)$, PCWP decreased mildly from $5.4 \pm 0.9 \quad$ to $\quad 4.4 \pm 0.6 \quad \mathrm{mmHg} \quad(\mathrm{P}<0.05)$, and transpulmonary pressure gradient (TPG) from $24 \pm 4$ to $18 \pm 3 \mathrm{mmHg}(\mathrm{P}<0.01) . \mathrm{SvO}_{2}$ increased from $76 \pm 3 \%$ to $83 \pm 3 \% \quad(\mathrm{P}<0.01)$. Regional tissue oxygenation increased on forehead from $72 \pm 2 \%$ to $76 \pm 1 \%$ $(\mathrm{P}<0.01)$ and did not change significantly on forelimb. With increasing EBF, the CVP gradually fell from $4.4 \pm 0.5$ to $2.6 \pm 0.7 \mathrm{mmHg}(\mathrm{P}<0.001)$.

Effects of the same ECMO protocol applied to HF model were considerably stronger. From EBF 1 to $4 \mathrm{l} / \mathrm{min}$ MAP increased from $52 \pm 5$ to $74 \pm 6 \mathrm{mmHg}$ $(\mathrm{P}<0.01)$ and carotid flow increased from $258 \pm 28$ to $410 \pm 34 \mathrm{ml} / \mathrm{min} \quad(\mathrm{P}<0.01)$. MPAP did not change significantly, nevertheless PCWP increased from $8.3 \pm 1.9$ to $10.3 \pm 1.8 \mathrm{mmHg}(\mathrm{P}<0.001)$, and $\mathrm{TPG}$ decreased from $27 \pm 4 \mathrm{mmHg}$ to $15 \pm 5 \mathrm{mmHg}$ $(\mathrm{P}<0.05) . \mathrm{SvO}_{2}$ improved from $56 \pm 6 \%$ to $84 \pm 4 \%$ $(\mathrm{P}<0.0001), \mathrm{rSO}_{2}$ on forehead increased from $52 \pm 4 \%$ to $66 \pm 3 \%(\mathrm{P}<0.01)$, and on forelimb from $58 \pm 3 \%$ to $65 \pm 3 \% \quad(\mathrm{P}<0.01)$. CVP decreased from $7.5 \pm 0.5$ to $5.1 \pm 0.4 \mathrm{mmHg}(\mathrm{P}<0.01)$.

$\mathrm{V}_{\mathrm{T}}$ and PEEP were set constant during the whole protocol to minimize the influence of lung air content to the EIT measurement. Nevertheless, for EBF 1 to 4 1/min mean airway pressure decreased in both groups, from $10.0 \pm 0.3$ to $9.1 \pm 0.4 \mathrm{cmH}_{2} \mathrm{O}(\mathrm{P}<0.001)$ in healthy circulation and from $9.9 \pm 0.5$ to $8.9 \pm 0.3 \mathrm{cmH}_{2} \mathrm{O}$ $(\mathrm{P}<0.05)$ in HF model. With increasing EBF, static lung compliance decreased in healthy circulation group from $31 \pm 2$ to $30 \pm 2 \mathrm{ml} / \mathrm{cmH}_{2} \mathrm{O} \quad(\mathrm{P}<0.001)$ but did not change in HF model. 

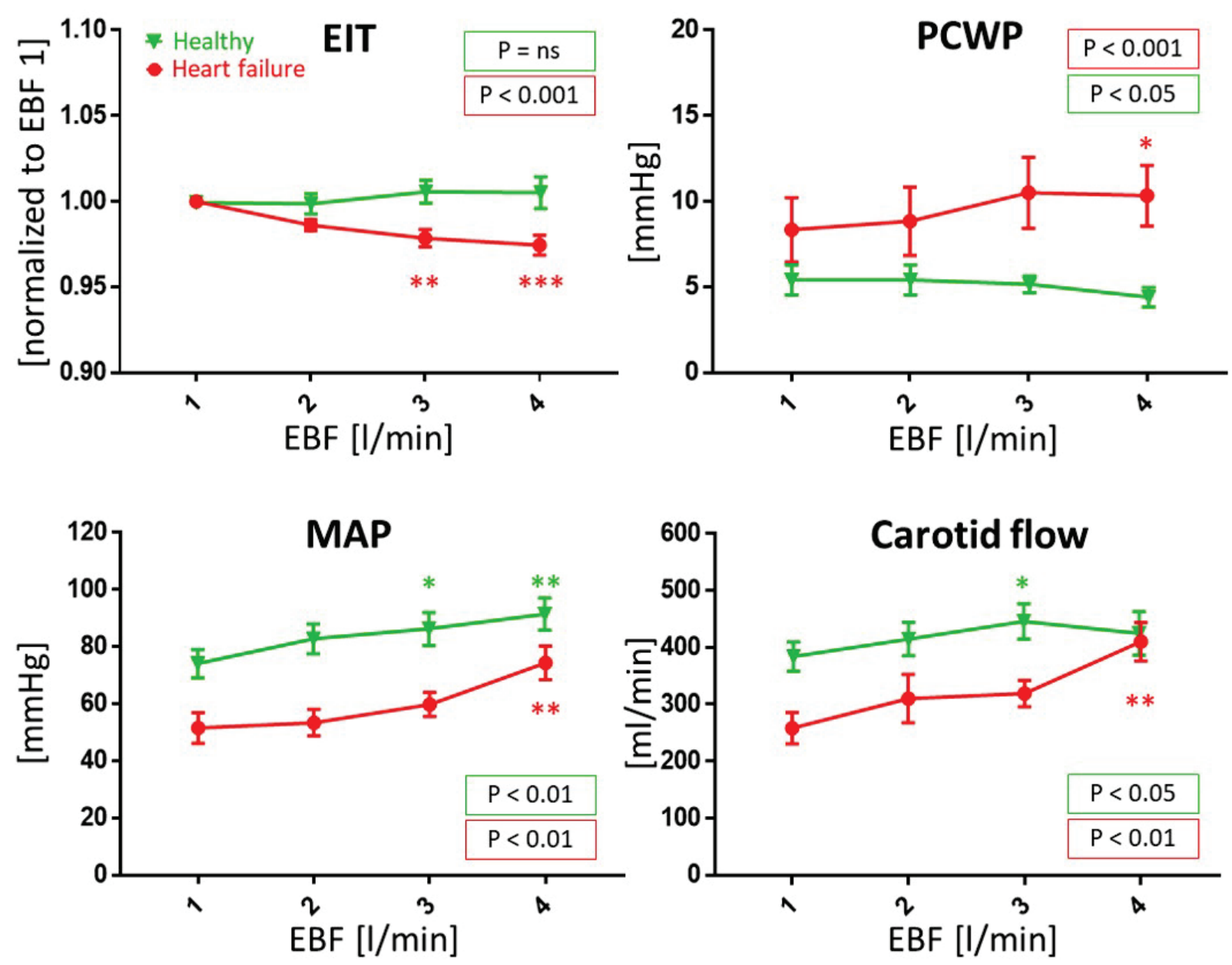

Fig. 3. The effect of veno-arterial membrane oxygenation blood flow (EBF) on selected hemodynamic parameters and EIT in a porcine model of healthy (green triangles) and heart failure (red dots) conditions. Means and SEMs shown here have descriptive meaning, for details of $\mathrm{P}$ values see the Methods. Values significantly different to $1 \mathrm{l} / \mathrm{min}$ (EBF 1 ) are marked with $*$ for $\mathrm{P}<0.05, * *$ for $\mathrm{P}<0.01$, $* * *$ for $\mathrm{P}<0.001$. The two $\mathrm{P}$ values in the legend reflect the whole EBF trend statistics. EBF - extracorporeal blood flow, EIT - electrical impedance of lung regions normalized to EBF 1 ( $1 \mathrm{l} / \mathrm{min})$, MAP - mean arterial pressure, PCWP - pulmonary capillary wedge pressure, ns - non-significant.

\section{Discussion}

Recent studies have reported the effect of increasing VA ECMO flow on the LV overload under severe heart failure condition. However, not enough attention has been paid to pulmonary edema which may consequently occur. The primary aim of this study was to evaluate the ability of EIT to distinguish even small changes in fluid content within the lung tissue related to VA ECMO operation. For this purpose, we have developed a custom-build algorithm for EIT signal analysis and together with other hemodynamic and oximetry parameters we used it to compare the effects of VA ECMO on healthy versus heart failure circulation.

Electrical impedance tomography for pulmonary fluid detection

Our key finding is that in a failing circulation supported by VA ECMO, the electrical impedance of pulmonary regions reduces with increasing $\mathrm{EBF}$ (1-4 l/min). This was significantly different from a healthy heart with identical ECMO support where there was no change in pulmonary region impedance (Fig. 3). Impedance is affected by numerous parameters such as pulmonary aeration, fluid infusion rate, patient movement, and electrodes position, so care was taken that these were kept constant. This is discussed in more detail here.

The changes of thoracic electrical impedance associated with the breathing cycle are one order of magnitude larger than the changes induced by the heartlung perfusion cycle or the fluid accumulation. Thus, several approaches have been proposed to separate lung regions and perfusion-related changes as well. This mainly includes auto-detection of the pulmonary region based on methods of identifying regions of interest such 
as frequency-based or statistic-based methods (Ferrario et al. 2012, Frerichs et al. 2017). However, some of these reconstructions do not correspond well to the expected lung anatomy. Isophase analysis, i.e. finding the regions of the same breathing phase (Riedel et al. 2009, Graf and Riedel 2017), realized by our own algorithm and areaaveraging of the impedance signal identified more relevant breathing regions.

Volume control lung-protective ventilation with constant tidal volume $\left(\mathrm{V}_{\mathrm{T}}\right)$ and constant PEEP was used to eliminate the effect of variable functional residual capacity and $\mathrm{V}_{\mathrm{T}}$ on electrical impedance, revealing thus much more delicate impedance effects caused by parameters like fluid accumulation in lungs. In heart failure conditions, the static lung compliance did not change significantly throughout the protocol, thus we assume that there was no influence of air volume on endexpiratory electrical impedance. In healthy condition there was a small decrease of static lung compliance $\left(0.9 \mathrm{ml} / \mathrm{cm} \mathrm{H}_{2} \mathrm{O}\right)$ accompanied with no impedance decrease. This result was not expected but its magnitude had no significant effect on the outcome. We hypothesize that it could be consequence of overall pulmonary deterioration often seen during general anesthesia.

The effect of fluid administration was minimized by keeping IV infusions constant throughout the protocol $(5-6 \mathrm{ml} / \mathrm{kg} / \mathrm{h})$, eliminating possible effects on the lung impedance. We suppose that constant lung impedance measured during running infusions indicates balanced fluid intake and loss.

Under constant ventilation and constant fluid infusions, we assume that the decrease in pulmonary region impedance during VA ECMO can be interpreted as an indirect marker of fluid accumulation. Increasing EBF generates higher afterload (represented by the rise in MAP - see Fig. 3) that impedes ventricular emptying of failing LV. This may be supported by the observation of LV filling pressure elevation (PCWP) despite significant reduction of preload (CVP) caused by ECMO drainage from the central veins.

Extracorporeal membrane oxygenation in healthy circulation

Interesting outputs of the study are the findings regarding the effects of increasing VA ECMO flow on healthy circulation. Our data indicate that even for the highest EBF $(80 \mathrm{ml} / \mathrm{kg} / \mathrm{min})$, which is about $75 \%$ of the resting cardiac output, the overall hemodynamics and oxygenation changed only little. In healthy circulation,
MAP increased by $23 \%$, carotid blood flow increased by $10 \%, \mathrm{rSO}_{2}$ on the forehead by $7 \%$, on the forelimb by $1 \%$, and $\mathrm{SvO}_{2}$ by $9 \%$. Thus, increased blood flow caused by VA ECMO could have been balanced by regulatory mechanisms, such as shunting the blood through arterio-venous anastomoses and by reducing cardiac output. Since carotid flow (a correlate for the global blood flow) increased only by $10 \%$, the latter option might be more involved. Indeed, during increasing of EBF from 1 to $4 \mathrm{l} / \mathrm{min}$, we noticed a significant decrease in CVP (by $41 \%$ ) and in MPAP (by $22 \%$ ). The TPG decreased in healthy as well as in the HF groups. This is likely a consequence of increased venous drainage by VA ECMO inflow cannula.

Aside from decreasing preload, VA ECMO increases left ventricular afterload. However, in healthy animals MAP increased only by $23 \%$ (Table 2). Furthermore, the electrical impedance in the pulmonary region did not change during EBF stepwise increases. Thus, we assume that fluids were neither depleted nor accumulated in the lungs in healthy animals due to VA ECMO operation. This was contrary to the observations in the HF condition.

An unexpected observation was the decrease in pulmonary compliance ( 40 to $32 \mathrm{ml} / \mathrm{cmH}_{2} \mathrm{O}$ ) soon after the VA ECMO insertion during the preparatory phase. This could be related to high pulmonary vasoreactivity of swine lungs that was triggered by the contact of blood with the extracorporeal circuit.

\section{Extracorporeal membrane oxygenation in heart failure}

In all animals we have succeeded in inducing moderate to severe acute heart failure with severe hypotension, hypoperfusion, increased filling pressures of both left and right ventricle (i.e. increased PCWP and CVP, respectively), and impaired oxygenation (Table 1). During the HF induction, the static lung compliance further decreased ( 32 to $25 \mathrm{ml} / \mathrm{cmH}_{2} \mathrm{O}$ ). This could have been caused by the onset of heart failure.

Recent studies have discussed EBF influence on a failing systemic circulation and our hemodynamic results are consistent with their findings (Burkhoff et al. 2015, Ostadal et al. 2015). In our study systemic hemodynamics and oximetry parameters increased considerably with increasing EBF from 1 to $41 / \mathrm{min}$, MAP by $44 \%$, carotid flow by $59 \%, \mathrm{SvO}_{2}$ by $49 \%$ (Table 2). The maximal EBF that was achieved in all animals was $80 \mathrm{ml} / \mathrm{kg} / \mathrm{min}$ (4 1/min). Only such high flow allowed for almost complete restoration of 
hemodynamics and oxygen delivery, demonstrated by $\mathrm{rSO}_{2}$ and $\mathrm{SvO}_{2}$. Both these parameters are used also clinically to monitor patients supported with VA ECMO since they are not dependent on the pulsatility of blood flow. The interpretation of $\mathrm{SvO}_{2}$ in terms of VA ECMO is rather complex as it is influenced by actual ratio of pulmonary and extracorporeal flows. In the settings of VA ECMO, the $\mathrm{SvO}_{2}$ reflects both delivery of oxygen and its extraction (Doufle and Ferguson 2016), but $\mathrm{SvO}_{2}$ values may vary in the venous blood of tissues supplied by native and extracorporeal circulation (Ostadal et al. 2018).

Despite reduced CVP and hence decreased right ventricular output caused by increasing VA ECMO drainage of the central veins, there was significant increase in the already elevated PCWP (Fig. 3). PCWP reflects both LV preload and LV cardiac output. If preload was reduced and PCWP increased, then this finding could again support the hypothesis that LV output (emptying) is compromised by increased LV afterload generated by increasing EBF. This is in accord with the findings from EIT discussed above.

\section{Limitations}

EIT is a highly sensitive method of fluid content monitoring as demonstrated above. The major EIT limitation is the dependence of impedance on several parameters that can change independently and might be difficult to separate in real-life scenarios. End-expiratory lung impedance can be influenced by other mechanisms than tidal volume and fluids, such as air trapping and/or air leaks. We consider air trapping was insignificant in our setup as no increase in intrinsic PEEP was noticed. Also, tidal volume and respiratory rate were low and there were no signs of airway obstruction. With adequate endotracheal cuff inflation, the air leak was only $2.1 \%$ of tidal volume in both groups and thus should not have affected the end-expiratory lung impedance. Moreover, it is known that EIT lacks the ability to reliably provide results in absolute units that would be unambiguously interpreted and compared among the patients, which is why we reported normalized EIT values solving that problem. In a recent study Da Silva Ramos et al. (2018) showed, that the differences in body dimension have a significant influence on the electrical impedance. To minimize this effect, we included animals of similar body weight. We expect that additional implementation of features like ventilation gating (based on airway pressure and flow) and cardiac cycle gating (based on ECG) would, in future, broaden the spectrum of observed parameters and make our analysis more robust. Moreover, this could enable the estimation of relative changes in systolic impedance variation (VonkNoordegraaf et al. 2000). We do not have a direct proof of lung fluid accumulation, e.g. transpulmonary thermodilution (TPTD). Nevertheless, Sobota et al. (2019) demonstrated that EIT is more sensitive compared to the TPTD in identifying the changes in lung fluids, as TPTD may not reflect small changes of lung fluids. Previous works have suggested that the pulmonary edema usually occurs after days of VA ECMO running (Lequier et al. 2017) and our protocol covered only short periods. Further work is needed to observe long-term VA ECMO influence on electrical impedance to evaluate lung fluid accumulation.

\section{Conclusion}

In heart failure conditions, the reduction of lung tissue electrical impedance was observed when VA ECMO flow was increased. In healthy circulation with VA ECMO, this impedance change was not detected. Under constant ventilation and fluid infusion this can be interpreted as transient fluid content changes in the lungs. We conclude that EIT could be considered helpful in monitoring the VA ECMO therapy and its effects on lung fluid content.

\section{Abbreviations}

CVP, central venous pressure; EBF, extracorporeal blood flow; EIT, electrical impedance tomography; etCO ${ }_{2}$, end-tidal $\mathrm{CO}_{2} ; \mathrm{FiO}_{2}$, fraction of inspired oxygen; $\mathrm{HF}$, heart failure; IM, intramuscular; IV, intravenous; LAD, left anterior descending coronary artery; LV, left ventricle; MAP, mean arterial pressure; MPAP, mean pulmonary artery pressure; PCWP, pulmonary capillary wedge pressure; ${ }_{\mathrm{p}} \mathrm{CO}$, cardiac output; $\mathrm{pCO}_{2}$, partial pressure of $\mathrm{CO}_{2} ; \mathrm{pO}_{2}$, partial pressure of oxygen; PEEP, positive end-expiratory pressure; PIP, peak inspiratory pressure; $\mathrm{rSO}_{2}$, regional oxygen saturation; SEM, standard error of the mean; $\mathrm{SvO}_{2}$, mixed venous oxygen saturation; TPG, transpulmonary pressure gradient; TPTD, transpulmonary thermodilution; VA ECMO, veno-arterial extracorporeal membrane oxygenation; $\mathrm{VF}$, ventricular fibrillation; $\mathrm{V}_{\mathrm{T}}$, tidal volume; $\Delta \mathrm{Z}$ (tidal volume), change of electrical impedance during breathing cycle; $\Delta \mathrm{Z}$ (EBF), change of electrical impedance during increasing $\mathrm{EBF}$. 


\section{Conflict of Interest}

There is no conflict of interest.

\section{Acknowledgements}

The authors wish to sincerely and gratefully acknowledge the advice and assistance of Jana Bortelová for help with animal care and of Jana Míšková, Tereza Vavř́ková, Alena Ehrlichová, Karel Kypta, Matěj Hrachovina, Vít Čapoun for technical support, and Alena Dohnalová for statistical analysis. This work was supported by Charles University research grant GA UK No. 538216 and SVV 260379.

\section{References}

ABRAMS D, COMBES A, BRODIE D: What's new in extracorporeal membrane oxygenation for cardiac failure and cardiac arrest in adults? Intens Care Med 40: 609-612, 2014. https://doi.org/10.1007/s00134-014-3212-0

ADLER A, AMYOT R, GUARDO R, BATES JH, BERTHIAUME Y: Monitoring changes in lung air and liquid volumes with electrical impedance tomography. J Appl Physiol (1985) 83: 1762-1767, 1997. https://doi.org/10.1152/jappl.1997.83.5.1762

BACHMANN MC, MORAIS C, BUGEDO G, BRUHN A, MORALES A, BORGES JB, COSTA E, RETAMAL J: Electrical impedance tomography in acute respiratory distress syndrome. Crit Care 22: 263, 2018. https://doi.org/10.1186/s13054-018-2195-6

BECHER T, WENDLER A, EIMER C, WEILER N, FRERICHS I: Changes in electrical impedance tomography findings of ICU patients during rapid infusion of a fluid bolus: a prospective observational study. Am J Respir Crit Care Med 199: 1572-1575, 2019. https://doi.org/10.1164/rccm.201812-2252LE

BORGES JB, SUAREZ-SIPMANN F, BOHM SH, TUSMAN G, MELO A, MARIPUU E, SANDSTROM M, PARK M, COSTA EL, HEDENSTIERNA G, AMATO M: Regional lung perfusion estimated by electrical impedance tomography in a piglet model of lung collapse. J Appl Physiol (1985) 112: 225-236, 2012. https://doi.org/10.1152/japplphysiol.01090.2010

BRECHOT N, DEMONDION P, SANTI F, LEBRETON G, PHAM T, DALAKIDIS A, GAMBOTTI L, LUYT CE, SCHMIDT M, HEKIMIAN G, CLUZEL P, CHASTRE J, LEPRINCE P, COMBES A: Intra-aortic balloon pump protects against hydrostatic pulmonary oedema during peripheral venoarterial-extracorporeal membrane oxygenation. Eur Heart J Acute Cardiovasc Care: 2048872617711169, 2017. https://doi.org/10.1177/2048872617711169

BURKHOFF D, SAYER G, DOSHI D, URIEL N: Hemodynamics of mechanical circulatory support. J Am Coll Cardiol 66: 2663-2674, 2015. https://doi.org/10.1016/j.jacc.2015.10.017

CARDINALE L, PRIOLA AM, MORETTI F, VOLPICELLI G: Effectiveness of chest radiography, lung ultrasound and thoracic computed tomography in the diagnosis of congestive heart failure. World J Radiol 6: 230-237, 2014. https://doi.org/10.4329/wjr.v6.i6.230

DA SILVA RAMOS FJ, HOVNANIAN A, SOUZA R, AZEVEDO LCP, AMATO MBP, COSTA ELV: Estimation of stroke volume and stroke volume changes by electrical impedance tomography. Anesth Analg 126: 102-110, 2018. https://doi.org/10.1213/ANE.0000000000002271

DONKER DW, BRODIE D, HENRIQUES JPS, BROOME M: Left ventricular unloading during veno-arterial ECMO: a review of percutaneous and surgical unloading interventions. Perfusion 34: 98-105, 2019. https://doi.org/10.1177/0267659118794112

DOUFLE G, FERGUSON ND: Monitoring during extracorporeal membrane oxygenation. Curr Opin Crit Care 22: 230-238, 2016. https://doi.org/10.1097/MCC.0000000000000309

FERRARIO D, GRYCHTOL B, ADLER A, SOLA J, BOHM SH, BODENSTEIN M: Toward morphological thoracic EIT: major signal sources correspond to respective organ locations in CT. IEEE Trans Biomed Eng 59: 3000-3008, 2012. https://doi.org/10.1109/TBME.2012.2209116

FRERICHS I, AMATO MB, VAN KAAM AH, TINGAY DG, ZHAO Z, GRYCHTOL B, BODENSTEIN M, GAGNON H, BOHM SH, TESCHNER E, STENQVIST O, MAURI T, TORSANI V, CAMPOROTA L, SCHIBLER A, WOLF GK, GOMMERS D, LEONHARDT S, ADLER A, and TREND study group: Chest electrical impedance tomography examination, data analysis, terminology, clinical use and recommendations: consensus statement of the TRanslational EIT developmeNt stuDy group. Thorax 72: 83-93, 2017. https://doi.org/10.1136/thoraxjnl-2016-208357 
FUHRMAN P, HERNAN L, ROTTA A: Pathophysiology of cardiac extracorporeal membrane oxygenation. Artificial Organs 23: 966-969, 1999. https://doi.org/10.1046/j.1525-1594.1999.06484.x

GRAF M, RIEDEL T: Electrical impedance tomography: Amplitudes of cardiac related impedance changes in the lung are highly position dependent. PLoS One 12: e0188313, 2017. https://doi.org/10.1371/journal.pone.0188313

HALA P, MLCEK M, OSTADAL P, JANAK D, POPKOVA M, BOUCEK T, LACKO S, KUDLICKA J, NEUZIL P, KITTNAR O: Regional tissue oximetry reflects changes in arterial flow in porcine chronic heart failure treated with venoarterial extracorporeal membrane oxygenation. Physiol Res 65 (Suppl 5): S621-S631, 2016. https://doi.org/10.33549/physiolres.933532

HALA P, MLCEK M, OSTADAL P, JANAK D, POPKOVA M, BOUCEK T, LACKO S, KUDLICKA J, NEUZIL P, KITTNAR O: Tachycardia-induced cardiomyopathy as a chronic heart failure model in swine. J Vis Exp, 2018. https://doi.org/10.3791/57030

HÁLA P, MLČEK M, OŠŤÁDAL P, POPKOVÁ M, JANÁK D, BOUČEK T, LACKO S, KUDLIČKA J, NEUŽIL P, KITTNAR O: Increasing venoarterial extracorporeal membrane oxygenation flow puts higher demands on left ventricular work in a porcine model of chronic heart failure. J Translat Med 18: 75, 2020. https://doi.org/10.1186/s12967-020-02250-x

ISHIKAWA K, AGUERO J, TILEMANN L, LADAGE D, HAMMOUDI N, KAWASE Y, SANTOS-GALLEGO CG, FISH K, LEVINE RA, HAJJAR RJ: Characterizing preclinical models of ischemic heart failure: differences between LAD and LCx infarctions. Am J Physiol Heart Circ Physiol 307: H1478-1486, 2014. https://doi.org/10.1152/ajpheart.00797.2013

JANAK D, HALA P, MLCEK M, POPKOVA M, LACKO S, KUDLICKA J, KITTNAR O: Detection of microembolic signals in the common carotid artery using Doppler sonography in the porcine model of acute heart failure treated by veno-arterial extracorporeal membrane oxygenation. Physiol Res 66 (Suppl 4): S529-S536, 2017. https://doi.org/10.33549/physiolres.933806

KIM H, PAEK JH, SONG JH, LEE H, JHEE JH, PARK S, YUN HR, KEE YK, HAN SH, YOO TH, KANG SW, KIM S, PARK JT: Permissive fluid volume in adult patients undergoing extracorporeal membrane oxygenation treatment. Crit Care 22: 270, 2018. https://doi.org/10.1186/s13054-018-2211-x

LACKO S, MLCEK M, HALA P, POPKOVA M, JANAK D, HRACHOVINA M, KUDLICKA J, HRACHOVINA V, OSTADAL P, KITTNAR O: Severe acute heart failure - experimental model with very low mortality. Physiol Res 67: 555-562, 2018. https://doi.org/10.33549/physiolres.933774

LEQUIER L, LORUSSO R, MACLAREN G, PEEK G, BROHAN TV: Extracorporeal Life Support: The ELSO Red Book. ELSO, 2017.

LI X, SHAO D, WANG G, JIANG T, WU H, GU B, CAO K, ZHANG J, QI L, CHEN Y: Effects of different LAD-blocked sites on the development of acute myocardial infarction and malignant arrhythmia in a swine model. J Thorac Dis 6: 1271-1277, 2014. https://doi.org/10.3978/j.issn.2072-1439.2014.07.22

MAKDISI G, WANG IW: Extra Corporeal Membrane Oxygenation (ECMO) review of a lifesaving technology. J Thorac Dis 7: E166-176, 2015. https://doi.org/10.3978/j.issn.2072-1439.2015.07.17

NOBLE TJ, HARRIS ND, MORICE AH, MILNES P, BROWN BH: Diuretic induced change in lung water assessed by electrical impedance tomography. Physiol Meas 21: 155-163, 2000. https://doi.org/10.1088/0967$\underline{3334 / 21 / 1 / 319}$

OSTADAL P, BELOHLAVEK J, BALIK M, RIHA H: ECMO - Extracorporeal Membrane Oxygenation. Manual for use in adult patients. Czech Republic, Maxdorf, 2018.

OSTADAL P, MLCEK M, KRUGER A, HALA P, LACKO S, MATES M, VONDRAKOVA D, SVOBODA T, HRACHOVINA M, JANOTKA M, PSOTOVA H, STRUNINA S, KITTNAR O, NEUZIL P: Increasing venoarterial extracorporeal membrane oxygenation flow negatively affects left ventricular performance in a porcine model of cardiogenic shock. J Transl Med 13: 266, 2015. https://doi.org/10.1186/s12967-015-0634-6

OSTADAL P, MLCEK M, STRUNINA S, HRACHOVINA M, KRUGER A, VONDRAKOVA D, JANOTKA M, HALA P, KITTNAR O, NEUZIL P: Novel porcine model of acute severe cardiogenic shock developed by upper-body hypoxia. Physiol Res 65: 711-715, 2016. https://doi.org/10.33549/physiolres.933294 
REINIUS H, BORGES JB, FREDEN F, JIDEUS L, CAMARGO ED, AMATO MB, HEDENSTIERNA G, LARSSON A, LENNMYR F: Real-time ventilation and perfusion distributions by electrical impedance tomography during one-lung ventilation with capnothorax. Acta Anaesthesiol Scand 59: 354-368, 2015. https://doi.org/10.1111/aas.12455

RIEDEL T, KYBURZ M, LATZIN P, THAMRIN C, FREY U: Regional and overall ventilation inhomogeneities in preterm and term-born infants. Intensive Care Med 35: 144-151, 2009. https://doi.org/10.1007/s00134-008$\underline{1299-\mathrm{x}}$

SOBOTA V, MÜLLER M, ROUBÍK K: Intravenous administration of normal saline may be misinterpreted as a change of end-expiratory lung volume when using electrical impedance tomography. Scientific Reports 9: 5775, 2019. https://doi.org/10.1038/s41598-019-42241-7

SOLEIMANI B, PAE WE: Management of left ventricular distension during peripheral extracorporeal membrane oxygenation for cardiogenic shock. Perfusion 27: 326-331, 2012. https://doi.org/10.1177/0267659112443722

SUZUKI Y, LYONS JK, YEUNG AC, IKENO F: In vivo porcine model of reperfused myocardial infarction: in situ double staining to measure precise infarct area/area at risk. Catheter Cardiovasc Interv 71: 100-107, 2008. https://doi.org/10.1002/ccd.21329

VONK-NOORDEGRAAF A, 2ND, JANSE A, MARCUS JT, BRONZWAER JG, POSTMUST PE, FAES TJ, DE VRIES PM: Determination of stroke volume by means of electrical impedance tomography. Physiol Meas 21: 285-293, 2000. https://doi.org/10.1088/0967-3334/21/2/308 